\title{
Literacy and Memory Decline Among Ethnically Diverse Elders
}

\author{
Jennifer J. Manly ${ }^{1,2.3}$, Pegah Touradji ${ }^{3}$, Ming-Xin Tang ${ }^{1.5}$, and Yaakov Stern ${ }^{1,2.3 .4}$ \\ Columbia University College of Physicians and Surgeons, New York, NY, USA, 'Cognitive Neuroscience Division, \\ Taub Institute for Research on Alzheimer's Disease and the Aging Brain, ${ }^{2}$ Department of Neurology, \\ ${ }^{3}$ G.H. Sergievsky Center, ${ }^{4}$ Department of Psychiatry, and ${ }^{5}$ Division of Biostatistics, School of Public Health
}

\begin{abstract}
Literacy may be a more powerful indicator of brain reserve than years of education. Literacy level may be a proxy for native intellectual capacity or life experience that can compensate for brain damage or provide brain reserve. Alternately, the experience of acquiring literacy skills may in itself change the organization of the brain and increase protection against cognitive decline. However, because people with low levels of literacy obtain poor scores on most cognitive measures, only longitudinal studies can elucidate the role of reading ability in reserve. We determined whether literacy skills could predict cognitive change in a sample of 136 English-speaking African American, Caucasian, and Hispanic elders selected from a longitudinal aging study in New York City. According to a physician's independent examination, all participants were nondemented throughout the four longitudinal assessments. Literacy level was assessed using the WRAT-3 reading subtest. After accounting for age at baseline and years of education, GEE analyses showed that elders with low levels of literacy had a steeper decline in both immediate and delayed recall of a word list over time as compared to high literacy elders. Our findings suggest that literacy skills are protective against memory decline among nondemented elders.
\end{abstract}

\section{INTRODUCTION}

Low education has been established as a significant risk factor for $\mathrm{AD}$ and other dementias (Kawas \& Katzman, 1999). A higher prevalence of Alzheimer's disease and dementia among elders with low levels of education has been found in Brazil (Caramelli et al., 1997), China (Hill et al., 1993; Zhang et al., 1990), Finland (Sulkava et al., 1985), France (Dartigues et al., 1991), Italy (Bonaiuto et al., 1990; Prencipe et al., 1996), Israel (Bowirrat, Treves, Friedland, \& Korczyn, 2001; Korczyn, Kahana, \& Galper, 1991), the Netherlands (Ott et al., 1995), Sweden (Fratiglioni et al., 1991; Gatz et al., 2001), and the United States (Callahan et al.,
1996; Gurland et al., 1995; Mortel, Meyer, Herod, \& Thornby, 1995). Higher incidence of dementia has been demonstrated in several studies (Evans et al., 1993; Letenneur, Commenges, Dartigues, \& Barberger-Gateau, 1994; Stern et al., 1994; White et al., 1994). Cognitive decline appears to be faster (Stern, Albert, Tang, \& Tsai, 1999; Teri, McCurry, Edland, Kukull, \& Larson, 1995; Unverzagt, Hui, Farlow, Hall, \& Hendrie, 1998) and associated with increased risk of mortality (Stern, Tang, Denaro, \& Mayeux, 1995) among highly educated minorities with Alzheimer's disease, which suggests that the level of brain pathology is greater by the time well educated individuals show the signs of dementia.

Address correspondence to: Jennifer Manly, Ph.D., G.H. Sergievsky Center, 630 West 168th Street P\&S Box 16, New York, NY 10032, USA. Tel.: +1-212-305-8604. Fax: +1-212-305-2426. E-mail: jjm71@ columbia.edu Accepted for publication: December 15, 2002. 
The studies cited thus far have demonstrated a link between education and dementia or Alzheimer's disease. But there is also evidence for a role of education in age-related cognitive decline. Several studies of normal aging have found more rapid cognitive and functional decline in individuals with lower educational attainment (Albert et al., 1995; Butler, Ashford, \& Snowdon, 1996; Chodosh, Reuben, Albert, \& Seeman, 2002; Christensen et al., 1997; Farmer, Kittner, Rae, Bartko, \& Regier, 1995; Snowdon, Ostwald, $\&$ Kane, 1989). These studies suggest that the same education-related factors that delay the onset of dementia also allow individuals to cope more effectively with changes encountered in normal aging.

Cognitive reserve has been suggested as the mechanism for the link between low education and higher risk of dementia observed in these studies (Katzman, 1993; Mortimer, 1988; Satz et al., 1993; Stern, 2002). Reserve, or the brain's ability to tolerate the effects of dementia pathology, may result from native ability or from the effects of lifetime experience. Years of education may serve as a proxy for reserve whether it results from ability or experience. In passive models of reserve (Stern, 2002), education would be a proxy for the brain's capacity (synaptic density or complexity) to tolerate either gradual or sudden insult. In active models, years of education would be an indicator of the brain's ability to compensate for pathology through more efficient use of existing cognitive networks or recruitment of alternate networks.

However, there are cases in which the relationship between education and risk for cognitive impairment or dementia is weakened or absent. Two large international studies of incident dementia found that illiteracy or low levels of education did not increase the risk of Alzheimer's disease among elders in India (Chandra et al., 2001 ) and West Africa (Hall et al., 1998; Hendrie, 2001). In fact, these studies had the lowest prevalence and incidence rates of dementia observed to date despite the fact that a large proportion of the populations lacked formal schooling or literacy training. This paradox serves to illuminate the difficulty in comparing cultural groups with disparate backgrounds. Reserve is measured by proxy variables (such as years of education, occupational level, or IQ measures), but there are a number of ways in which cultural, racial, and economic factors may affect the predictive power of these proxies.

\section{Ethnicity and Native Ability}

Studies showing that early intellectual or linguistic ability predicts who will develop dementia clinically in later life (Whalley et al., 2000) or neuropathologically (Snowdon et al., 1996) provide strong support to the theory that years of education is a proxy for brain or cognitive characteristics that are already present at birth. That is, the same cognitive strengths or robust brain structures that allow for academic or occupational success, are also less susceptible to sudden or gradual insult.

However, years of education may not be an accurate representation of native ability among minority or immigrant elders whose educational opportunities were limited due to institutionalized racism and poverty. Minorities with strong intellectual abilities may not achieve academic or occupational success because their opportunities are limited by societal forces beyond their native intellect or drive to succeed. Although such individuals may be powerful or influential in their community, their abilities may not be reflected in years of schooling or traditional indicators of occupational status. Thus, the relationship between years of education and native ability would be weakened among ethnic minorities, leading to underestimates of the relationship between education and cognitive decline.

Evidence for the relatively weak association between years of education and dementia risk among African Americans is provided by a study conducted in Indianapolis (Hall, Gao, Unverzagt, \& Hendrie, 2000). Childhood residence (rural vs. urban) and educational level was evaluated in a random sample of 223 African American elders, 180 of whom were neurologically normal and 43 who had AD. Childhood rural residence, combined with fewer than 7 years of school, was associated with an increased risk of AD. The authors hypothesized that low education by itself is not a major risk factor within African Americans, but is a marker for other deleterious 
socioeconomic or environmental influences in childhood. The major limitation of this study is its cross-sectional design, since African American elders with low education who were raised in rural settings might have performed badly on the cognitive tests used to diagnose dementia simply as a function of their cultural and educational background.

Native ability has also been operationalized using tests such as IQ measures or vocabulary tests. There is ample evidence that scores on traditional cognitive tests underestimate the functional abilities of African Americans (see review, Manly \& Jacobs, 2001) and other ethnic minorities (Ardila, 1995; Wong, Strickland, Fletcher-Janzen, Ardila, \& Reynolds, 2000) at least in part due to subjects' lack of familiarity with items or level of comfort and confidence during the testing session. Therefore, indices of reserve (whether assessed either in childhood or as an adult) may also underestimate the strength of the relationship between native ability and protection from cognitive decline among ethnic minorities.

\section{Ethnicity and Educational Experience}

Rather than a reflection of innate ability, years of education could be an indicator of lifetime experiences that change the brain during childhood or adult life and thus create a reserve against disease pathology. However, use of years of education to represent a direct effect of experience on the brain or cognition is problematic when employed among ethnic minorities. This is due to the increased discordance between years of education and quality of education among ethnic minorities. Previous studies revealed that elderly African Americans have reading skills significantly below their self-reported education level (Albert \& Teresi, 1999; Baker, Johnson, Velli, \& Wiley, 1996; Manly, Jacobs, Touradji, Small, \& Stern, 2002). These discrepancies have been shown to be related to the inferior funding of segregated Black schools as compared to White Southern schools and most integrated Northern schools (Anderson, 1988; Hanushek, 1989; Hedges, Laine, \& Greenwald, 1994; Margo, 1985, 1990; O’Neill, 1990; Smith, 1984; Smith \& Welch, 1977; Welch, 1966, 1973).

\section{The Literacy Advantage}

We propose that the use of literacy as an estimate of the quality of education will serve as a more meaningful proxy for reserve among ethnic minorities. The utility of literacy in studies of cognitive ability among normal elders was recently demonstrated by our group in research that sought to determine if discrepancies in quality of education could explain differences in neuropsychological test scores between African American and White elders matched on years of education. A comprehensive cognitive battery was administered to a sample of nondemented African American and non-Hispanic White participants in an epidemiologic study of normal aging and dementia in the Northern Manhattan community. The Reading Recognition subtest from the Wide Range Achievement Test - Version 3 (WRAT-3: Wilkinson, 1993) was used as an estimate of quality of education. African American elders obtained significantly lower scores than Whites on measures of word list learning and memory, figure memory, abstract reasoning, fluency, and visuospatial skill even though the groups were matched on years of education. However, after adjusting the scores for WRAT-3 reading score, the overall effect of race was greatly reduced, and racial differences on all tests (except category fluency and a drawing measure) became nonsignificant. This study suggests that literacy could be a more sensitive proxy for reserve than years of education, because it more accurately reflects the quality of the educational experience provided to ethnic minority elders. In addition, literacy could be a more accurate reflection of native ability because it does not assume that all individuals get the same amount of learning from a certain grade level; the fact that some excel more than others or seek learning outside of school will be reflected in measurements of literacy.

Some limited evidence is available regarding the effect of literacy on age-related cognitive change among neurologically normal adults. Ardila, Ostrosky-Solis, Rosselli, and Gomez, (2000) conducted a cross-sectional study of 865 Spanish-speaking Mexican adults between the ages of 16 and 85 . They found that verbal memory performance declined more sharply with age among illiterates than among people with 10 or 
more years of education. Measures of other cognitive domains (such as visuospatial skill, attention, and verbal fluency) showed other patterns of change with age by education level. The authors did not indicate how illiteracy was determined (it appears to be equivalent with having no formal schooling), and thus the effects of literacy and years of education are indistinguishable. Further, the cross-sectional design leaves open the possibility that the interactions between age and education are cohort effects. Nevertheless, the findings of this research are in keeping with the theoretical role of literacy we have outlined here, and encourage further investigation.

The overall goal of the current study was to explore the relationship of literacy level to change in memory ability over time among an ethnically diverse sample of nondemented elders. Specifically, we wanted to determine if literacy was a stronger predictor of memory decline (and thus a more sensitive indicator of reserve) than years of education or racial/ethnic classification, although each of these variables were expected to influence baseline scores. We focused our analyses on immediate and delayed recall measures from a verbal word list learning task, since these measures are sensitive to age-related memory decline and mark the earliest signs of Alzheimer's disease.

\section{METHOD}

\section{Research Participants}

The current sample was selected from participants in the Washington Heights-Inwood Columbia Aging Project (WHICAP), a community-based, epidemiologic study of dementia in the ethnically diverse neighborhoods of Northern Manhattan, New York. The WHICAP study follows a random sample of elderly Medicare recipients residing in selected census tracts of Washington/ Hamilton Heights and Inwood. Participants are followed prospectively and receive annual medical, neurologic, and neuropsychological evaluations. The population from which participants were drawn is comprised of individuals from several different countries of origin and representing three broadly defined ethnic categories (i.e., Hispanic, African American, and non-Hispanic White).

All potential participants were age 65 and above and were fluent in English. In order to control for possible effects of language use, we excluded any individuals whose first language was not English. Potential participants were excluded if they had a history of Parkinson's Disease, stroke, head injury with loss of consciousness, alcohol abuse, or serious mental illness such as depression or schizophrenia. WHICAP participants who showed neurological or functional signs of dementia or cognitive impairment without dementia at any time point were excluded from the current analyses. This determination was made on the basis of a physician's clinical examination, which included a rating of daily functioning (see Procedures section) and was independent of the participant's performance on the neuropsychological battery. Of these nondemented participants, only those with four completed evaluations were considered for this analysis.

\section{Procedure}

\section{Medical Evaluation}

A physician recorded the medical history and medications in a semistructured format. Neurological and brief physical examinations were performed, including assessment of extrapyramidal signs. Functional status was measured using Part 1 of the Blessed Dementia Rating Scale (BDRS; Blessed, Tomlinson, \& Roth, 1968) and the Schwab and England rating scale of activities of daily living (Boller, Mizutani, Roessmann, \& Gambetti, 1980). From this information, the physician determined whether the participant met criteria for delirium, dementia, or cognitive impairment without dementia using Diagnostic and Statistical Manual of Mental Disorders - Fourth Edition (American Psychiatric Association, 1987) criteria.

\section{Word List Learning and Memory}

The Selective Reminding Test (SRT; Buschke \& Fuld, 1974) was administered at baseline and each follow-up evaluation. Participants were given six trials to learn a list of 12 unrelated words. After each recall attempt, they were reminded only of the words that had not been successfully recalled. The total number of words recalled over these six trials was recorded. Delayed incidental recall was assessed after a 15-min delay. Three alternate forms of the SRT in which the word lists are matched on frequency and length were used.

\section{Reading Level}

English reading level was measured using the Reading Recognition subtest from the Wide Range Achievement Test - Version 3 (Wilkinson, 1993). On this test, participants are asked to name letters and pronounce words out of context. The words are listed in order of decreasing familiarity and increasing phonological complexity. Consistent with the standard instructions for administration, a basal of five correct words or 
letters and a ceiling of 10 incorrect words or letters was used.

\section{Statistical Methods}

Longitudinal analysis was performed using Generalized Estimated Equations (GEE; Liang \& Zeger, 1986). GEE is based on regression models that do not require outcome measures to be independent of each other (in this case, the repeated neuropsychological test scores), and it does not require that these measures have a normal distribution. GEE uses the correlations among outcome measures to improve statistical power. For this study, GEE analyses were performed to assess for differences in longitudinal performance among the literacy groups. The GEE analyses used literacy groups split on the median WRAT-3 score. The primary variables of interest in these analyses were literacy group (high vs. low), time, and the interaction term literacy group $\times$ time. Preliminary analyses showed that results did not differ whether time was included as a continuous or categorical variable. All final analyses included time as a continuous variable, measured from the point of baseline testing.

We evaluated age (67-79 vs. $>80$ years), ethnicity (White vs. ethnic minority), gender, and years of education (high vs. low, split at the median of 12 years) for inclusion as covariates, as well as the interactions of each of these variables with time. For each GEE analysis, we first included all covariates in the model, and then trimmed back the model, retaining only those covariates that significantly contributed to prediction of memory test score.

Regression coefficients from these GEE analyses represent associations between a neuropsychological score and variables included in the model. A significant literacy group effect indicates a significant difference between the two groups at the baseline or any subsequent evaluation, with a positive regression coefficient indicating that the group with high literacy obtained higher scores than the low literacy group. A significant time effect indicates a change of test scores over time; a negative coefficient indicates that both groups are declining over time. The most important variable under consideration is the literacy $\times$ time interaction. A significant literacy $\times$ time regression coefficient indicates that there is a difference in the rate of change of test scores between the two groups.

\section{RESULTS}

\section{Sample Characteristics}

A total of 136 participants met exclusion and inclusion criteria. Participants were stratified into two literacy groups based on the median performance of the group on the WRAT-3 reading test $($ median $=47)$. Table 1 presents the demographics of the two groups. As expected, the low literacy group had fewer years of education and low literacy participants were more likely to be ethnic minorities than the high literacy group. The high literacy group was $61 \%$ White, 39\% African American, and $0 \%$ Hispanic, while the low literacy group was $24 \%$ White, $67 \%$ African American and $9 \%$ Hispanic. The groups did not differ from each other on age or gender composition. Mean follow-up duration was 5.1 years $(S D=1.1)$ and did not differ within the two literacy groups.

\section{GEE Analyses of Literacy Groups}

GEE analyses were performed to determine differences in change in SRT total recall performance

Table 1. Characteristics of the Two Literacy Groups Used for Analysis.

\begin{tabular}{|c|c|c|c|c|c|c|}
\hline & \multicolumn{3}{|c|}{ Low literacy group } & \multicolumn{3}{|c|}{ High literacy group } \\
\hline & $M$ & $S D$ & Range & $M$ & $S D$ & Range \\
\hline Age & 79.8 & 5.8 & $67-94$ & 80.3 & 5.2 & $68-94$ \\
\hline Years of education ${ }^{\mathrm{a}}$ & 10.6 & 3.4 & $0-16$ & 13.0 & 3.2 & $1-18$ \\
\hline WRAT- 3 reading score ${ }^{b}$ & 40.3 & 7.8 & $0-47$ & 51.2 & 2.2 & $48-56$ \\
\hline Sex, $\%$ female & $76.1 \%$ & & & $63.8 \%$ & & \\
\hline Ethnicity, \% minority ${ }^{c}$ & $76.1 \%$ & & & $39.1 \%$ & & \\
\hline
\end{tabular}

Note. Number of subjects for low literacy group and high literacy group are 67 and 69 , respectively. ${ }^{t} t(134)=4.34 ; p<.001$.

${ }^{b} t(134)=13.22 ; p<.001$.

${ }^{c} \chi^{2}(1)=19.56 ; p<.001$. 


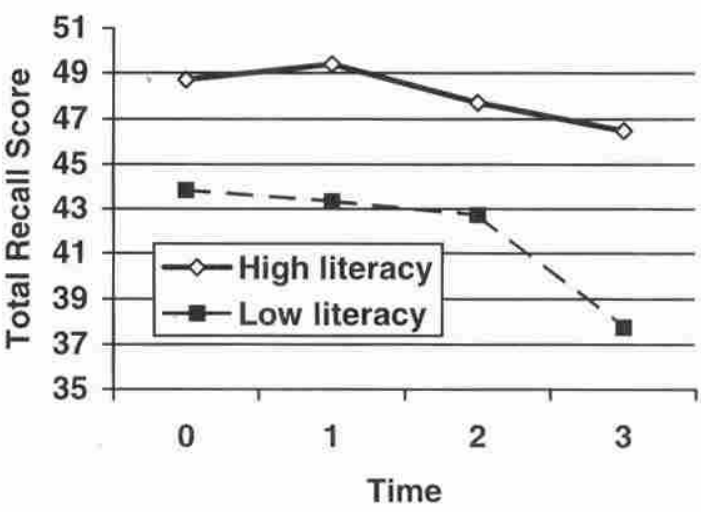

Fig. 1. Change in Selective Reminding Test total recall score over time.

between the two literacy groups. When each of the covariates was entered into the model, there was no effect of gender, ethnicity, or interaction of any of the covariates with time. The final model included two significant covariates, indicating that age $(\beta=-2.92, p=.006)$ and education $(\beta=2.8$, $p=.005$ ) had main effects on SRT total recall score in the expected directions. There was a significant literacy group effect $(\beta=3.17, p=.002)$ and a significant time effect $(\beta=-1.09, p<.001)$. There was also a significant positive literacy $x$ time interaction $(\beta=0.61, p=.025)$, indicating that the low literacy group had a steeper decline in total recall scores compared with the high literacy group. These results are presented graphically in Figure 1. When this analysis was repeated using separate White $(n=58)$ and nonWhite ( $n=78$ ) groups, the strength and the direction of the regression coefficients for each of the effects was essentially unchanged as compared to the analysis with the combined sample.

Using SRT delayed recall as the dependent variable in a GEE analysis yielded similar results; only years of education $(\beta=0.93, p=.005)$ was significant among the added covariates, but there was a significant literacy group effect $(\beta=0.73$, $p=.031)$ and a significant time effect $(\beta=$ $-0.23, p<.001)$. There was also a significant positive literacy $\times$ time interaction $(\beta=0.17$, $p=.035$ ), indicating that the low literacy group had a steeper decline in delayed recall scores compared with the high literacy group. The profile of SRT delayed recall scores over time

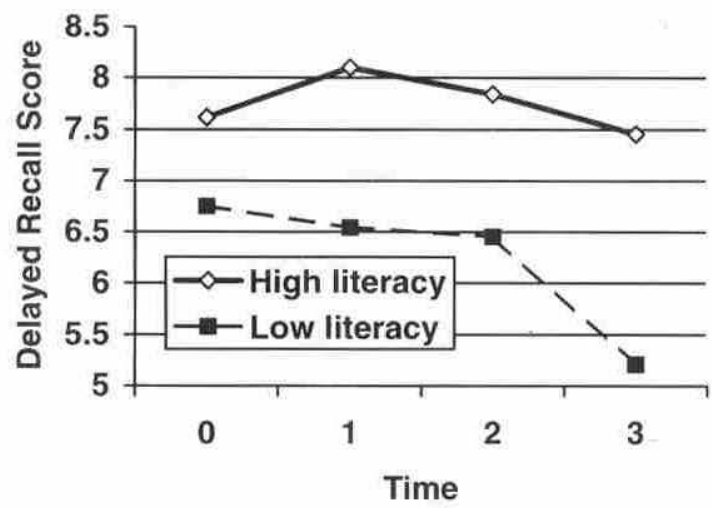

Fig. 2. Change in Selective Reminding Test delayed recall score over time.

for high and low literacy groups is shown in Figure 2. Again, there was essentially no difference in the regression coefficients when the analysis was performed using separate White and nonWhite groups.

\section{DISCUSSION}

Elders with both high and low levels of literacy declined in immediate and delayed memory over time; however, the decline was more rapid among low literacy elders. This suggests that high literacy skills do not provide complete preservation of memory skills but rather a slowing of agerelated decline. All participants had normal overall cognition and were functioning normally in daily activities. Thus the decline in memory scores was not associated with the onset of a dementia disorder.

There were no interactions between time and either years of education or ethnicity, suggesting that, in this diverse population of normal elders, literacy was the most sensitive predictor of memory decline. Unlike many prior studies that examined the relationship of education to dementia or normal aging, we did not find that low education (less than 12 years) was a risk factor for cognitive decline.

Our results are thus similar to those obtained in West Africa (Hall et al., 1998; Hendrie, 2001) and India (Chandra et al., 2001). In our sample, over $57 \%$ were ethnic minorities; as in West Africa and 
India, most individuals had drastically fewer opportunities for education (as is obvious by the high rates of low literacy). In such settings, those with high native intellect may not have been able to achieve academic success commensurate with their ability. High and low literacy groups would thus not differ in innate intellect or in the resistance to pathology it may confer (Gatz et al., 2001). The fact that levels of dementia remain low in areas where illiteracy rates are high supports the theory that reserve is the result of innate traits rather than acquired through education.

Literacy could be a more accurate reflection of native ability than years of education. While educational experience certainly contributes to literacy, individuals may have opportunities to enhance their literacy throughout their lifetime that are not reflected by years of education. Gifted individuals will be more likely to develop literacy skills regardless of their opportunity to attend formal schooling.

We found that cognitive change over time was better predicted by literacy than by years of education. However, both literacy and years of education significantly affected baseline scores on immediate and delayed recall. The main effect of literacy was greater than the main effect of education for total recall scores, while the converse was true for delayed recall scores. This finding extends previous studies which showed that literacy captures an aspect of educational experience, which is not accounted for by years of education alone, and that it can add to the prediction of how ethnically and linguistically diverse individuals should perform on cognitive tests (Manly et al., 1999; Manly et al., 2002; Reis \& Castro-Caldas, 1997; Weiss, Reed, Kligman, \& Abyad, 1995). The meaning of years of education is not commensurate between ethnic and racial groups (Kaufman \& Cooper, 1995), making literacy a more sensitive indicator of the educational experience of minority elders. Research on cognitive reserve could benefit from such an indicator to help deconstruct the various components of education that might contribute to resistance against pathology.

Learning to read and write may fundamentally change the functional architecture of the brain
(Petersson, Reis, \& Ingvar, 2001), allowing it to actively compensate for age-related changes. Literacy changes the way we process and represent information, primarily phonological (Lecours et al., 1987; Matute, Leal, Zaraboso, Robles, \& Cedillo, 1997; Petersson et al., 2001; Rosselli, Ardila, \& Rosas, 1990; Scribner \& Cole, 1981 ) but also nonverbal stimuli (Ardila, Rosselli, \& Rosas, 1989; Manly et al., 1999). The process of acquiring and using literacy skills may also increase the synaptic density of the brain, like other factors which contribute to an "enriched environment" (Diamond, 1988).

A strength of the current study is its longitudinal design. Our analysis of change over time avoids detection bias, because variables such as years of education, literacy, and cultural background that affect baseline measurement are likely to have a similar effect on subsequent measurements. However, the assumption that these biases will not affect change in score over time is problematic if well educated, highly literate, and culturally mainstream individuals are able to benefit from practice more than less educated, low literate ethnic minorities.

Although all participants in our studies were diagnosed as normal at all time points, the possibility remains that some elders suffered from an early stage of Alzheimer's pathology which might be sufficient to impair their reading performance yet remain undetected by the physician's assessment. If present, such cases of preclinical dementia would be likely to appear disproportionately in the low literacy group. However, if singleword reading task performance remains stable during the development of dementia, the WRAT-3 would reflect literacy rather than pathology in all cases. Although the utility of single-word reading measures such as the WRAT-3 in premorbid IQ estimation is controversial (Dura, Myers, \& Freathy, 1989; Johnstone, Callahan, Kapila, \& Bouman, 1996; Johnstone \& Wilhelm, 1996; O'Carroll, 1995; Storandt, Stone, \& LaBarge, 1995), one longitudinal study of incident dementia (Schmand, Geerlings, Jonker, \& Lindeboom, 1998) concluded that reading level remains a valid estimate of premorbid ability in mild and questionable dementia. Ideally, childhood measures of literacy would be used to predict development of 
cognitive decline later in life, thus avoiding confounding from effects of preclinical dementia on reading skill. This technique was elegantly demonstrated in studies showing that low scores on measures of intelligence in childhood (Whalley et al., 2000) and low linguistic ability in the early 1920s (Snowdon et al., 1996) were associated with low cognitive test scores and dementia in old age.

Future study should extend the current findings beyond normal aging to determine the role of literacy in predicting conversion of normal elders to questionable dementia or MCI and dementia. Investigators should also detail the relationship of literacy to functional change or memory complaints over time; if high literacy reflects reserve, it should also be associated with relative preservation of activities of daily living. This approach would avoid the problems of shared variance that arise when one verbal test (literacy) is used to predict another (verbal memory).

Although years of education was taken into account in the current study, it is possible that statistical methods could not perfectly equalize the two literacy groups on all variables associated with schooling. It may be desirable to examine literacy as independent of education through longitudinal investigation of a cohort of elders without any formal education who did or did not achieve literacy (e.g., Manly et al., 1999; Reis \& Castro-Caldas, 1997).

Both native ability and educational experience contribute to an individual's literacy level. However, the factors that determine the strength of each contribution tend to differ among ethnic or racial groups. When comparing between ethnic groups, differences in the availability of educational opportunity are likely to predominate. Racism, poverty, and other societal forces may have prevented some individuals with high native ability from gaining literacy skills, so literacy scores are a better proxy for quality of education in between-group comparisons. Within the same ethnic or racial group, disparities in educational opportunity may not be as strong, making literacy more likely to reflect ability to achieve academic success. In this case, literacy may be more appropriately used as a proxy for an individual's innate intellectual ability.

\section{ACKNOWLEDGMENTS}

This research was supported by federal grants AG16206 (J. Manly), AG07232 (R. Mayeux), the Alzheimer's Association, and the New York City Speakers Fund for Biomedical Research - Toward the Science of Patient Care. The authors thank Rosann Costa for her help with data management, Maria Gonzalez-Diaz for assistance with scheduling and interviewing participants, and Tavis Allison for his valuable editorial support for this manuscript.

\section{REFERENCES}

Albert, M.S., Jones, K., Savage, C.R., Berkman, L., Seeman, T., Blazer, D., \& Rowe, J.W. (1995). Predictors of cognitive change in older persons: MacArthur studies of successful aging. Psychology and Aging, 10, 578-589.

Albert, S.M., \& Teresi, J.A. (1999). Reading ability, education, and cognitive status assessment among older adults in Harlem, New York City. American Journal of Public Health, 89, 95-97.

American Psychiatric Association. (1987). Diagnostic and Statistical Manual of Mental Disorders (Rev. 3rd ed.). Washington, DC: American Psychiatric Press Inc.

Anderson, J.D. (1988). The education of Blacks in the South, 1860-1935. Chapel Hill: University of North Carolina Press.

Ardila, A. (1995). Directions of research in crosscultural neuropsychology. Journal of Clinical and Experimental Neuropsychology, 17, 143-150.

Ardila, A., Ostrosky-Solis, F., Rosselli, M., \& Gomez, C. (2000). Age-related cognitive decline during normal aging: The complex effect of education. Archives of Clinical Neuropsychology, 15, 495-513.

Ardila, A., Rosselli, M., \& Rosas, P. (1989). Neuropsychological assessment in illiterates: Visuospatial and memory abilities. Brain and Cognition, 11 , 147-166.

Baker, F.M., Johnson, J.T., Velli, S.A., \& Wiley, C. (1996). Congruence between education and reading levels of older persons. Psychiatric Services, 47, 194-196.

Blessed, G., Tomlinson, B.E., \& Roth, M. (1968). The association between quantitative measures of senile change in the cerebral grey matter of elderly subjects. British Journal of Psychology, 114 , 797-811.

Boller, F., Mizutani, T., Roessmann, U., \& Gambetti, P. (1980). Parkinson's disease, dementia, and Alzheimer's disease: Clinicopathological correlations. Annals of Neurology, I, 329-335. 
Bonaiuto, S., Rocca, W.A., Lippi, A., Luciani, P., Turtu, F., Cavarzeran, F., \& Amaducci, L. (1990). Impact of education and occupation on prevalence of Alzheimer's disease (AD) and multi-infarct dementia (MID) in Appignano, Macerata Province, Italy. Neurology, 40(Suppl. 1), 346.

Bowirrat, A., Treves, T., Friedland, R.P., \& Korczyn, A.D. (2001). Prevalence of Alzheimer's type dementia in an elderly Arab population. European Journal of Epidemiology, 8, 119-123.

Buschke, H., \& Fuld, P.A. (1974). Evaluating storage, retention, and retrieval in disordered memory and learning. Neurology, 24, 1019-1025.

Butler, S.M., Ashford, J.W., \& Snowdon, D.A. (1996). Age, education, and changes in the Mini-Mental State Exam scores of older women: Findings from the Nun Study. Journal of the American Geriatrics Society, 44, 675-681.

Callahan, C.M., Hall, K.S., Hui, S.L., Musick, B.S., Unverzagt, F.W., \& Hendrie, H.C. (1996). Relationship of age, education, and occupation with dementia among a community-based sample of African Americans. Archives of Neurology, 53, 134-140.

Caramelli, P., Poissant, A., Gauthier, S., Bellavance, A., Gauvreau, D., Lecours, A.R., \& Joanette, Y. (1997). Educational level and neuropsychological heterogeneity in dementia of the Alzheimer type. Alzheimer Disease and Associated Disorders, 11. 9-15.

Chandra, V., Pandav, R., Dodge, H.H., Johnston, J.M., Belle, S.H., DeKosky, S.T., \& Ganguli, M. (2001). Incidence of Alzheimer's disease in a rural community in India: The Indo-US study. Neurology, 57 . 985-989.

Chodosh, J., Reuben, D.B., Albert, M.S., \& Seeman, T.E. (2002). Predicting cognitive impairment in high-functioning community-dwelling older persons: MacArthur Studies of Successful Aging. Journal of the American Geriatrics Society, 50, 1051-1060.

Christensen, H., Korten, A.E., Jorm, A.F., Henderson, A.S., Jacomb, P.A., Rodgers, B., \& Mackinnon, A.J. (1997). Education and decline in cognitive performance: Compensatory but not protective. International Journal of Geriatric Psychiatry, 12, 323-330.

Dartigues, J.F., Gagnon, M., Michel, P., Letenneur, L., Commenges, D., Barberger-Gateau, P., Auriacombe, S., Rigal, B., Bedry, R., Alperovitch, A., Orgogozo, J.M., Henry, P., Loiseau, P., Salamon, R., \& et Groupe d'Etude Paquid (1991). Le programme de recherche paquid sur l'epidemiologie de la demence methodes et resultats initiaux. Revue Neurologique (Paris), 147, 225-230.

Diamond, M.C. (1988). Enriching heredity: The impact of the environment on the anatomy of the brain. New York: The Free Press.
Dura, J.R., Myers, E.G., \& Freathy, D.T. (1989). Stability of the Wide Range Achievement Test in an adolescent psychiatric inpatient setting. Educational and Psychological Measurement, 49, 253-256.

Evans, D.A., Beckett, L.A., Albert, M.S., Hebert, L.E., Scherr, P.A., Funkenstein, H.H., \& Taylor, J.O. (1993). Level of education and change in cognitive function in a community population of older persons. Annals of Epidemiology, 3, 71-77.

Farmer, M.E., Kittner, S.J., Rae, D.S., Bartko, J.J., \& Regier, D.A. (1995). Education and change in cognitive function: The epidemiologic catchment area study. Annals of Epidemiology, 5, 1-7.

Fratiglioni, L., Grut, M., Forsell, Y., Viitanen, M., Grafstrom, M., Holmen, K., Ericsson, K., Backman, L., Ahlbom, A., \& Winblad, B. (1991). Prevalence of Alzheimer's disease and other dementias in an elderly urban population: Relationship with age, sex and education. Neurology, 41, 1886-1892.

Gatz, M., Svedberg, P., Pederson, N.L., Mortimer, J.A., Berg, S., \& Johansson, B. (2001). Education and the risk of Alzheimer's disease: Findings from the study of dementia in Swedish twins. Journals of Gerontology, 56B, 292-300.

Gurland, B.J., Wilder, D., Cross, P., Lantigua, R., Teresi, J.A., Barret, V., Stern, Y., \& Mayeux, R. (1995). Relative rates of dementia by multiple case definitions, over two prevalence periods, in three cultural groups. American Journal of Geriatric Psychiatry, 3, 6-20.

Hall, K.S., Gao, S., Unverzagt, F.W., \& Hendrie, H.C. (2000). Low education and childhood rural residence: Risk for Alzheimer's disease in African Americans. Neurology, 54, 95-99.

Hall, K.S., Gureje, O., Gao, S., Ogunniyi, A., Hui, S.L., Baiyewu, O., Unverzagt, F.W., Oluwole, S., \& Hendrie, H.C. (1998). Risk factors and Alzheimer's disease: A comparative study of two communities. Australian and New Zealand Journal of Psychiatry, 32, 698-706.

Hanushek, E. (1989). The impact of differential expenditures on school performance. Educational Researcher, 18, 45-51.

Hedges, L.V., Laine, R.D., \& Greenwald, R. (1994). Does money matter? A meta-analysis of studies of the effects of differential school inputs on student outcomes. Educational Researcher, 23, 5-14.

Hendrie, H.C. (2001). Exploration of environmental and genetic risk factors for Alzheimer's disease: The value of cross cultural studies. Current Directions in Psychological Science, 10, 98-101.

Hill, L.R., Klauber, M.R., Salmon, D.P., Yu, E.S.H., Liu, W.T., Zhang, M., \& Katzman, R. (1993). Functional status, education, and the diagnosis of dementia in the Shanghai survey, Neurology, 43, 138-145. 
Johnstone, B., Callahan, C.D., Kapila, C.J., \& Bouman, D.E. (1996). The comparability of the WRAT-R Reading Test and NAART as estimates of premorbid intelligence in neurologically impaired patients. Archives of Clinical Neuropsychology, 11, 513-519.

Johnstone, B., \& Wilhelm, K.L. (1996). The longitudinal stability of the WRAT-R reading subtest: Is it an appropriate estimate of premorbid intelligence? Journal of the International Neuropsychological Society, 2, 282-285.

Katzman, R. (1993). Education and the prevalence of dementia and Alzheimer's disease. Neurology, 43, 13-20.

Kaufman, J.S., \& Cooper, R.S. (1995). Epidemiologic research on minority health: In search of the hypothesis. Public Health Reports, 110, 662-666.

Kawas, C.H., \& Katzman, R. (1999). Epidemiology of dementia and Alzheimer's disease. In R.D. Terry, R. Katzman, S.S. Sisodia, \& K.L. Bick (Eds.), Alzheimer's Disease (pp. 95-116). Philadelphia: Lippincott Williams \& Wilkins.

Korczyn, A.D., Kahana, E., \& Galper, Y. (1991). Epidemiology of dementia in Ashkelon, Israel. Neuroepidemiology, 10, 100.

Lecours, A.R., Mehler, J., Parente, M.A., Caldeira, A., Cary, L., Castro, M.J., Dehaut, F., Delgado, R., Gurd, J.. Karmann, D.F., Jakubovitz, R., Osorio, Z., Cabral, L.S., \& Junquerira, A.M.S. (1987). Illiteracy and brain damage. 1. Aphasia testing in culturally contrasted populations (control subjects). Neuropsychologia, 25, 231-245.

Letenneur, L., Commenges, D., Dartigues, J.F., \& Barberger-Gateau, P. (1994). Incidence of dementia and Alzheimer's disease in elderly community residents of south-western France. International Journal of Epidemiology, 23, 1256-1261.

Liang, K.Y., \& Zeger, S.L. (1986). Longitudinal data analysis using generalized linear models. Biometrika, 73, 13-22.

Manly, J.J., \& Jacobs, D.M. (2001). Future directions in neuropsychological assessment with African Americans. In F.R. Ferraro (Ed.), Minority and cross-cultural aspects of neuropsychological assessment. The Netherlands: Swets and Zeitlinger.

Manly, J.J., Jacobs, D.M., Sano, M., Bell, K., Merchant, C.A., Small, S.A., \& Stern, Y. (1999). Effect of literacy on neuropsychological test performance in nondemented, education-matched elders. Journal of the International Neuropsychological Society, 5, 191-202.

Manly, J.J., Jacobs, D.M., Touradji, P., Small, S.A., \& Stern, Y. (2002). Reading level attenuates differences in neuropsychological test performance between African American and White elders. Journal of the International Neuropsychological Society, 8, 341-348.
Margo, R.A. (1985). Disenfranchisement, school finance, and the economics of segregated schools in the United States south, 1980-1910. New York: Garland Publishing.

Margo, R.A. (1990). Race and schooling in the South, 1880-1950: An economic history. Chicago: University of Chicago Press.

Matute, E., Leal, F., Zaraboso, A., Robles, A., \& Cedillo, C. (1997). Influence of literacy level on stick constructions in non-brain-damaged subjects. Journal of the International Neuropsychological Society, 3, 32.

Mortel, K.F., Meyer, J.S., Herod, B., \& Thornby, J. (1995). Education and occupation as risk factors for dementia of the Alzheimer and ischemic vascular types. Dementia, 6, 55-62.

Mortimer, J.A. (1988). Do psychosocial risk factors contribute to Alzheimer's disease. In A.S. Henderson \& J.H. Henderson (Eds.), Etiology of dementia of Alzheimer's type (pp. 39-52). Chichester: Wiley.

O'Carroll, R. (1995). The assessment of premorbid ability: A critical review. Neurocase, 1, 83-89.

O'Neill, J. (1990). The role of human capitol in earning differences between Black and White men. Journal of Economic Perspectives, 4, 25-45.

Ott, A., Breteler, M.M., van Harskamp, F., Claus, J.J., van der Cammen, T.J., Grobbee, D.E., \& Hofman. A. (1995). Prevalence of Alzheimer's disease and vascular dementia: Association with education. The Rotterdam study [see comments]. British Medical Journal, 310, 970-973.

Petersson, K.M., Reis, A., \& Ingvar, M. (2001). Cognitive processing in literate and illiterate subjects: A review of some recent behavioral and functional neuroimaging data. Scandinavian Journal of Psychology, 42, 251-267.

Prencipe, M., Casini, A.R., Ferretti, C., Lattanzio, M.T. Fiorelli, M., \& Culasso, F. (1996). Prevalence of dementia in an elderly rural population: Effects of age, sex, and education. Journal of Neurology Neurosurgery and Psychiatry, 60, 628-633.

Reis, A., \& Castro-Caldas, A. (1997). Illiteracy: A cause for biased cognitive development. Journal of the International Neuropsychological Society, 3, $444-450$.

Rosselli, M., Ardila, A., \& Rosas, P. (1990). Neuropsychological assessment in illiterates. II. Language and praxic abilities. Brain and Cognition, 12, 281-296.

Satz, P., Morgenstern, H., Miller, E.N., Selnes, O.A., McArthur, J.C., Cohen, B.A., Wesch, J., Becker, J.T., Jacobson, L., D'Elia, L.F., van Gorp, W., \& Visscher, B. (1993). Low education as a possible risk factor for cognitive abnormalities in HIV-1: Findings from the Multicenter AIDS Cohort Study 
(MACS). Journal of Acquired Immune Deficiency Syndromes, 6, 503-511.

Schmand, B., Geerlings, M.I., Jonker, C., \& Lindeboom, J. (1998). Reading ability as an estimator of premorbid intelligence: Does it remain stable in emergent dementia? Journal of Clinical and Experimental Neuropsychology, 20, 42-51.

Scribner, S., \& Cole, M. (1981). The Psychology of Literacy. Cambridge: Harvard University Press.

Smith, J.P. (1984). Race and human capital. American Economic Review, 4, 685-698.

Smith, J.P., \& Welch, F. (1977). Black-White male wage ratios: 1960-1970. American Economic Review, 67, 323-328.

Snowdon, D.A., Kemper, S.J., Mortimer, J.A., Greiner, L.H., Wekstein, D.R., \& Markesbery, W.R. (1996). Linguistic ability in early life and cognitive function and Alzheimer's disease in late life. Findings from the Nun Study. Journal of the American Medical Association, 275, 528-532.

Snowdon, D.A., Ostwald, S.K., \& Kane, R.L. (1989). Education, survival and independence in elderly Catholic sisters, 1936-1988. American Journal of Epidemiology, 130, 999-1012.

Stern, Y. (2002). What is cognitive reserve? Theory and research application of the reserve concept. Journal of the International Neuropsychological Society, 8, 448-460.

Stern, Y., Albert, S., Tang, M.-X., \& Tsai, W.-Y. (1999). Rate of memory decline in $\mathrm{AD}$ is related to education and occupation: Cognitive reserve? Neurology, 53, 1942-1947.

Stern, Y., Gurland, B., Tatemichi, T.K., Tang, M.X., Wilder, D., \& Mayeux, R. (1994). Influence of education and occupation on the incidence of Alzheimer's disease. Journal of the American Medical Association, 271, 1004-1010.

Stern, Y., Tang, M.X., Denaro, J., \& Mayeux, R. (1995). Increased risk of mortality in Alzheimer's disease patients with more advanced educational and occupational attainment. Annals of Neurology, 37, 590-595.

Storandt, M., Stone, K., \& LaBarge E. (1995). Deficits in reading performance in very mild dementia of Alzheimer type. Neuropsychology, 9, 174-176.

Sulkava, R., Wikstrom, J., Aromaa, A., Raitasalo, R., Lahtinen, V., Lahtela, K., \& Palo, J. (1985).
Prevalence of severe dementia in Finland. Neurology, 35, 1025-1029.

Teri, L., McCurry, S.M., Edland, S.D., Kukull, W.A., \& Larson, E.B. (1995). Cognitive decline in Alzheimer's disease: A longitudinal investigation of risk factors for accelerated decline. Journals of Gerontology: Biological Sciences and Medical Sciences, 50A, M49-M55.

Unverzagt, F.W., Hui, S.L., Farlow, M.R., Hall, K.S., \& Hendrie, H.C. (1998). Cognitive decline and education in mild dementia. Neurology, 50, 181-185.

Weiss, B.D., Reed, R., Kligman, E.W., \& Abyad, A. (1995). Literacy and performance on the MiniMental State Examination. Journal of the American Geriatric Society, 43, 807-810.

Welch, F. (1966). Measurement of the quality of education. American Economic Review, 56, 379-392.

Welch, F. (1973). Black-White differences in returns to schooling. American Economic Review, 63, 893-907.

Whalley, L.J., Starr, J.M., Athawes, R., Hunter, D., Pattie, A., \& Deary, I.J. (2000), Childhood mental ability and dementia. Neurology, 55, 1455-1459.

White, L., Katzman, R., Losonczy, K., Salive, M., Wallace, R., Berkman, L., Taylor, J., Fillenbaum, G., \& Havlik, R. (1994). Association of education with incidence of cognitive impairment in three established populations for epidemiological studies of the elderly. Journal of Clinical Epidemiology, 47, 363-374.

Wilkinson, G.S. (1993). Wide Range Achievement Test 3 - Administration Manual. Wilimington, DE: Jastak Associates, Inc.

Wong, T.M., Strickland, T.L., Fletcher-Janzen, E., Ardila, A., \& Reynolds, C.R. (2000). Theoretical and practical issues in the neuropsychological assessment and treatment of culturally dissimilar patients. In E. Fletcher-Janzen, T.L. Strickland, \& C.R. Reynolds (Eds.), Handbook of cross-cultural neuropsychology (pp. 3-18). New York: Kluwer Academic/Plenum Publishers.

Zhang, M., Katzman, R., Salmon, D., Jin, H., Cai, G., Wang, Z., Qu, G., Grant, I., Yu, E., Levy, P., Klauber, M.R., \& Liu, W.T. (1990). The prevalence of dementia and Alzheimer's disease in Shanghai, China: Impact of age, gender and education. Annals of Neurology, 27, 428-437. 
Copyright $@ 2003$ EBSCO Publishing 